\section{Asymptomatic vertebral fracture: a wolf in sheep's clothing?}

Francisco Bandeira'

$\mathrm{V}$ arious methods are available for the detection of the so-called morphometric vertebral fracture in patients who have low bone density but do not present with the classical symptoms of severe back pain due to vertebral collapse. The semiquantitative (SQ) method was developed for the purpose of correcting the subjective evaluation of radiographs and is widely used in epidemiological studies and clinical trials (1). It consists of an assessment of the height of vertebral bodies at the anterior, middle and posterior portions and the evaluation of the percentage of apparent reduction between them, grading the severity of the fracture as follows: Grade 0, when there is no fracture; Grade I, when there is a $20-25 \%$ reduction in vertebral body height; Grade II, when the reduction is between 25 and $40 \%$; and Grade III when the reduction is $>40 \%$. The assessment of vertebral fractures can also be made by the algorithm-based qualitative $A B Q$ Jiang method, which is a modified approach for the visual diagnosis of vertebral fractures (2). Vertebral fracture is identified when there is evidence of central terminal plate depression and not only by the reduction in the vertebral height itself. As criteria for the presence of fractures the $A B Q$ Jiang method uses evidence of osteoporotic endplate depression, with or without apophysis or cortical fracture.

The semiquantitative approach can be applied during bone mineral density (BMD) evaluation by the dual-energy $\mathrm{x}$-ray absorptiometry technique, also known as vertebral fracture assessment (VFA). Although conventional radiography of the spine is considered the standard method for the detection of vertebral fractures, VFA exposes the patient to lower radiation, has a lower cost and may be less operator-dependent (3). One potential disadvantage of conventional radiographic vertebral morphometry is related to the geometric distortions of the vertebral bodies inherent in the use of cone-beam geometry technique, in which each point on the radiograph is magnified and distorted in different ways. Compared with the center of the radiograph, which is less magnified and viewed at a more perpendicular angle, the periphery (edge) is more magnified and viewed at a more oblique angle. This issue of obliquity is minimized with VFA, particularly when performed with the patient in the supine position (3). Conventional visual radiographs are useful in identifying degenerative vertebral disease, which may resemble fractures when seen on VFA with automatic contour delineation of the vertebral bodies.

In this issue of the Archives Muszkat and cols. (4) report data on the prevalence of vertebral fractures by VFA/DXA in 188 postmenopausal women, of whom $75 \%$ were receiving treatment with bisphosphonates. They found that $17 \%$ had moderate to severe fractures. Fifty-six percent of the fractures occurred in the thoracic spine and $28 \%$ were considered severe. BMD values were not significantly different between those with and without fractures, but the latter were older and had significantly less fat mass, suggesting that general health and frailty may be an important factor related to the risk of vertebral fractures, as found in a recent study in old men (5).

The incidence of morphometric vertebral fractures ranges from $570 / 100,000$ person-years in men to $1070 / 100,000$ person-years in women (6). As such fractures may
1 Division of Endocrinology, University of Pernambuco Medical School, Recife, PE, Brazil
Correspondence to: Francisco Bandeira Disciplina de Endocrinologia, Faculdade de Ciências Médicas Universidade de Pernambuco Av. Rui Barbosa, 1435 52050-450 - Recife, PE, Brazil fbandeira@gmail.com

Received on Mar/25/2015 Accepted on Mar/25/2015

DOI: 10.1590/2359-3997000000017 
be detected in patients with BMD in the osteopenia range, evaluation of the vertebral morphometry is a valuable tool in identifying the high-risk patient for future fractures irrespective of BMD values (7). Moreover, the decision on a more prolonged use of bisphosphonates in the long-term treatment of low BMD in postmenopausal women may also depend on whether the patient has a vertebral fracture or not $(8)$.

The prevalence of vertebral fractures by VFA in postmenopausal women aged 59-70 years has been reported to be $4.3 \%$ using vertebral heights less than 3 SD from reference values (McCloskey criteria) and confirmed by the Genant method (9), with $17 \%$ of them having mild vertebral deformities (vertebral heights between -2 and -2.99 SD from reference values). Likewise, an increased prevalence of vertebral fractures has been reported in several conditions associated with bone fragility, including endocrine (10-13), inflammatory $(14,15)$ and cardio-pulmonary diseases $(16,17)$.

Several studies have demonstrated that the presence of an asymptomatic vertebral fracture may predispose the patient to a worse health outcome. It may be associated with a decrease in quality of life, reflecting the frailty of the elderly $(5,18)$. It may result in an increased risk of future fractures, especially at the hip, with all its devastating consequences (19), and also in an increase in total mortality (20).

The paper by Muszkat and cols. highlights the importance of detecting asymptomatic vertebral fractures in patients with low bone mass who are at increased risk for future fracture. It is therefore to be hoped that the availability of VFA will result in a more widespread use of this approach.

Disclosure: no potential conflict of interest relevant to this article was reported.

\section{REFERENCES}

1. Genant HK, Wu CY, Van Kujik C, Nevitt MC. Vertebral fracture assessment using a semiquantitative technique. J Bone Miner Res. 2003;8(9):1137-48.

2. Jiang G, Eastell R, Barrington NA, Ferrar L. Comparison of methods for the visual identification of prevalent vertebral fracture in osteoporosis. Osteoporos Int. 2004;15(11):887-96.

3. Hospers IC, Van der Laan J, Zeebregts C, Nieboer P, Wolffenbuttel $B$, Dierckx $R$, et al. Vertebral fracture assessment in supine position: comparison by using conventional semiquantitative radiography and visual radiography. Radiology. 2009;251(3):822-8.

4. Muszkat P, Camargo M, Peters B, Kunii I, Lazaretti-Castro M. Digital vertebral morphometry performed by DXA: a valuable opportunity for identifying fractures during bone mass assessment. Arch Endocrinol Metab. 2015;59(2):98-104.
5. Borges CN, de Almeida JM, Lima D, Cabral M, Bandeira F. Prevalence of morphometric vertebral fractures in old men and the agreement between different methods in the city of Recife, Brazil. Rheumatol Int. 2014;34(10):1387-94.

6. European Prospective Osteoporosi Study (EPOS) Group, Felsenberg D, Silman AJ, Lunt M, Armbrecht G, Ismail AA, Finn JD, et al. Incidence of vertebral fracture in Europe: results from the European Prospective Osteoporosis Study (EPOS). J Bone Miner Res. 2002;17(4):716-24.

7. Van der Klift M, De Laet C, McCloskey E Hofman A, Pols H. The incidence of vertebral fractures in men and women:The Rotterdam study. J Bone Miner Res. 2002;17(6):716-24.

8. Bandeira F, de Paula F, Lazaretti-Castro M, Premaor M. Targets in osteoporosis treatment. Arq Bras Endocrinol Metab. 2014;58(5):409-10.

9. Kanterewicz E, Puigoriol E, García-Barrionuevo J, del Rio L, Casellas M, Peris P; Frodos Research Group. Prevalence of vertebral fractures and minor vertebral deformities evaluated by DXA-assisted vertebral fracture assessment (VFA) in a population-based study of postmenopausal women: the FRODOS Osteoporos Int. 2014;25(5):1455-64.

10. Zhukouskaya VV, Eller-Vainicher C, Vadzianava VV, Shepelkevich AP, Zhurava IV, Korolenko GG, et al. Prevalence of morphometric vertebral fractures in patients with type 1 diabetes. Diabetes Care. 2013;36(6):1635-40.

11. Viegas M, Costa C, Lopes A, Griz L, Medeiro MA, Bandeira F. Prevalence of osteoporosis and vertebral fractures in postmenopausal women with type 2 diabetes mellitus and their relationship with duration of the disease and chronic complications. J Diabetes Complications. 2011;25(4):216-21.

12. Mazziotti G, Mancini T, Mormando M, De Menis E, Bianchi A, Doga $M$, et al. High prevalence of radiological vertebral fractures in women with prolactin-secreting pituitary adenomas. Pituitary. 2011;14(4):299-306.

13. Eller-Vainicher C, Battista C, Guarnieri V, Muscarella S, Palmieri S, Salcuni AS, et al. Factors associated with vertebral fracture risk in patients with primary hyperparathyroidism. Eur J Endocrinol. 2014;171(3):399-406.

14. Vázquez MA, Lopez E, Montoya MJ, Giner M, Pérez-Temprano R, Pérez-Cano R. Vertebral fractures in patients with inflammatory bowel disease compared with a healthy population: a prospective case-control study. BMC Gastroenterol. 2012;12:47.

15. Ulu MA, Batmaz İ, Dilek B, Çevik R. Prevalence of osteoporosis and vertebral fractures and related factors in patients with ankylosing spondylitis. Chin Med J (Engl). 2014;127(15):2740-7.

16. Silva $\mathrm{HC}$, Pinheiro MM, Genaro PS, Castro $\mathrm{CH}$, Monteiro $\mathrm{CM}$, Fonseca FA, et al. Higher prevalence of morphometric vertebral fractures in patients with recent coronary events independently of BMD measurements. Bone. 2013;52(2):562-7.

17. Carter JD, Patel S, Sultan FL, Thompson ZJ, Margaux H, Sterrett $A$, et al. The recognition and treatment of vertebral fractures in males with chronic obstructive pulmonary disease. Resp Med. 2008;102(8):1165-72.

18. Cockerill W, Lunt M, Silman AJ, Cooper C, Lips P, Bhalla AK, et al. Health-related quality of life and radiographic vertebral fracture. Osteoporos Int. 2004;15(2):113-9.

19. Ismail AA, Cockerill W, Cooper C, Finn JD, Abendroth K, Parisi G, et al. Prevalent vertebral deformity predicts incident hip though not distal forearm fracture: results from the European Prospective Osteoporosis Study. Osteoporos Int. 2001;12(2):85-90.

20. Hasserius R, Karlsson MK, Nilsson BE, Redlund-Johnell I, Johnell O. European Vertebral Osteoporosis Study. Prevalent vertebral deformities predict increased mortality and increased fracture rate in both men and women: a 10-year population-based study of 598 individuals from the Swedish cohort in the European Vertebral Osteoporosis Study. Osteoporos Int. 2003;14(1):61-8. 